Research Article

\title{
Experimental Investigation on Out-of-Plane Flexural and Shear Performance of Half Steel-Concrete Slabs
}

\author{
Quanquan Guo $\mathbb{D}^{1}{ }^{1}$ Peiyao Zhang, ${ }^{1}$ and Lieang Yang ${ }^{2}$ \\ ${ }^{1}$ Department of Civil Engineering, Beihang University, Beijing 100191, China \\ ${ }^{2}$ Department of Assets \& Logistic Management, Renmin University of China, Beijing 100191, China \\ Correspondence should be addressed to Quanquan Guo; qq_guo@buaa.edu.cn
}

Received 18 May 2020; Revised 23 August 2020; Accepted 8 September 2020; Published 29 September 2020

Academic Editor: Elhem Ghorbel

Copyright (C) 2020 Quanquan Guo et al. This is an open access article distributed under the Creative Commons Attribution License, which permits unrestricted use, distribution, and reproduction in any medium, provided the original work is properly cited.

Half steel-concrete slabs have been used in nuclear power plants and high-rise buildings as floor and roof panels. In order to study the failure mechanism, fifteen one-way Half-SC slabs with different steel faceplate thicknesses, stud numbers, shear span ratios, and volume tie bar ratios were tested under three-point or four-point loading. Mid-span deflections, strains of steel faceplate and concrete, and slippage between concrete and steel faceplate were measured. The result shows that Half-SC slabs exhibited four types of failure mode: flexure, shear, balanced, and interface slippage failure. Flexural failure was initiated by the tensile yield of the steel plate and followed by concrete crushing, which was similar to reinforced concrete slabs. In shear failure, when the shear span ratio is greater than 1.5, the steel plate in the shear-compression zone would achieve yield strength, and the ultimate failure is caused by the concrete crushing between the loading point and the support or by excessive plastic deformation of steel faceplate. This is significantly different from that of the reinforced concrete slabs. The increases in the volume tie bar ratio could postpone the occurrence of shear failure and even converted failure mode to flexural failure. The flexural strength was calculated. Based on a tiearch model, the calculation equation of shear strength was proposed. The calculated results agree well with the experimental data. Besides, these formulas were a good predictor of the transition between bending failure and shear failure with the shear span ratio.

\section{Introduction}

Half steel-concrete (Half-SC) slab [1] is a relatively new type of structure, in which a steel plate is placed on one side of the slab and reinforcing bars are placed on the other side. In comparison to steel-concrete (SC) Sandwich slab [2], the "half" means that only one side of the concrete is reinforced by steel faceplate, as shown in Figure 1. The steel faceplate is attached to concrete with headed studs to ensure deformation compatibility. Ties or other mechanical connectors, such as steel angles and channels, can be used to connect reinforcing bars and steel faceplate and improve lateral shear resistance.

Compared with traditional reinforced concrete (RC) slabs, Half-SC slabs have some advantages. For example, the steel faceplate acts as both longitudinal reinforcement and mold during concrete pouring, which can improve construction efficiency. Half-SC slabs were originally developed as horizontal bearing components of a steel faceplate reinforced concrete (SC) composite structure system in nuclear power plants (NPPs). They were firstly used in CAP1400 NPP [3] and HTR-PM NPP [4] in Rongcheng, Shandong. More recently, they have been used in high-rise buildings as floor panels [5] and bridges as deck panels [6].

In the past two decades, limited research has been done on Half-SC structures. Among others, Akita et al. [7] conducted a test on a square Half-SC slab $(1.2 \mathrm{~m} \times 1.2 \mathrm{~m})$ under bidirectional in-plane load with a pure shear stress state. They found that the failure mode of Half-SC slabs was between RC slabs and SC slabs, and the calculation method of the skeleton curve for Half-SC slabs was similar to that of SC slabs. Takeuchi et al. [8] studied the out-of-plane performance of seven Half-SC slabs with different shear span ratios, plate thicknesses, and tie bars spacing. The failure modes were mainly shear and interface slip caused by the failure of shear studs. Yang et al. [9] conducted bending tests on four Half-SC slab specimens. The results showed that the 


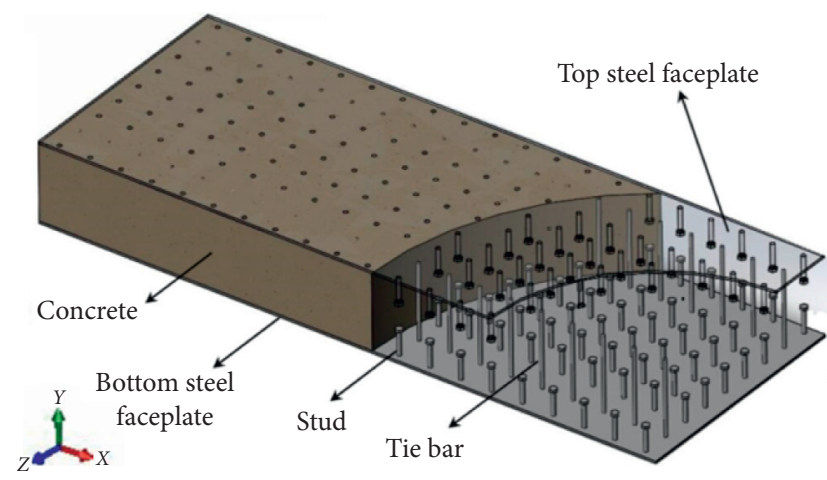

(a)

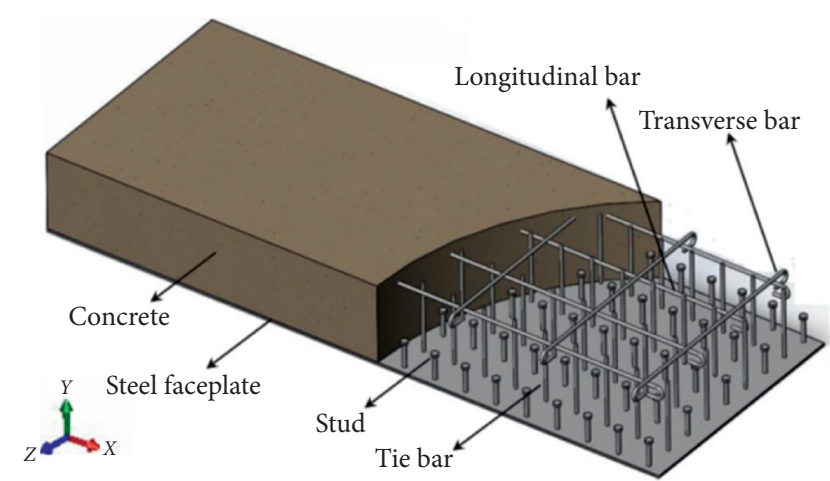

(b)

Figure 1: (a) SC slab and (b) Half-SC slab.

specimens with full-composite connection had high flexural strength and ductility, and their failure modes were similar to those of the reinforced concrete beams. Wu et al. [10] conducted out-of-plane loading tests on nine Half-SC slab specimens. A set of formulas to calculate the flexural capacity of Half-SC slabs considering the slip effect at the interface were derived. The Half-SC slab specimens in Yang et al. [9] and $\mathrm{Wu}$ et al.'s [10] experiments were equipped with longitudinal reinforcement at the bottom of the specimen, which were different from practical engineering applications. The calculation formulas presented by $\mathrm{Wu}$ et al. [10] were mainly based on the slip effect between steel faceplate and concrete which can be avoided by reasonable construction measures; thus, their utility was limited.

The existing research studies flexural and shear failure independently and cannot reveal the transition law between shear failure and flexural failure. It is impossible to fully understand the mechanical behavior of the Half-SC slab. In this paper, the out-of-plane performance of 15 Half-SC slab specimens was tested by three-point and four-point symmetric loading, including four types of failure modes: flexural, shear, balanced, and interface slippage failure (the stud connection is a partial composite connection). During the tests, mid-span deflections, strains of steel faceplates and concrete, and slippage between concrete and steel faceplates were measured. The strain and crack developments of all specimens were analyzed, and the effects of the thickness of steel plate, number of studs, shear span ratio, and tie bars ratio on mechanical properties were compared. The flexural strength was calculated. The shear strength was calculated by a tie-arch model.

\section{Experimental Program}

2.1. Details of Specimens. Two groups of specimens with a total of 15 Half-SC slab specimens were designed and tested. For group I, there were five specimens named HSC1-1 to HSC1-5, which were designed to study the effects of steel faceplate thickness and the number of studs on the mechanical performance of Half-SC slab. The intended failure mode was a flexural failure. HSC1-1 and HSC1-2 were the same, which served as control specimens. For group II, there were ten specimens named HSC2-1 to HSC2-10, which were designed to study the effects of steel faceplate thickness, the number of studs, the shear span ratio, and the volume tie bar ratio. The intended failure mode was a shear failure. HSC2-3 and HSC2-6 were the same, which served as control specimens. Section details and design parameters of the specimens are presented in Figure 2 and Table 1, respectively.

The type names of bolts were M6×35 and M10 ×60 according to the Chinese standard GB/T5782-2000 (eqv ISO $4014: 1999)$ [11]. The number of studs $\left(n_{\text {stud }}\right)$ outside of the loading point (including shear-compression and cantilever zones outside the support) can be calculated as follows [12]:

$$
n_{\text {stud }}=\frac{A_{\mathrm{p}} f_{\mathrm{yp}}}{V_{\mathrm{u}, \mathrm{stud}}},
$$

where $A_{\mathrm{p}}$ and $f_{\mathrm{yp}}$ represent the cross-section area and yield strength of the bottom faceplate, respectively. $V_{\mathrm{u} \text {,stud }}$ can be calculated as follows [12]:

$$
V_{\mathrm{u}, \mathrm{stud}} \leq 0.64 A_{\mathrm{stud}} f_{\mathrm{u}, \text { stud }}
$$

where $A_{\text {stud }}$ and $f_{\text {u,stud }}$ represent the effective cross-section area and ultimate tensile strength of the stud, respectively.

Except for HSC1-3, HSC1-4, and HSC2-4, all specimens used full composite connection, which means that the studs with the number of $n_{\text {stud }}$ were evenly distributed in the shear-compression zone, and the same spacing was used in the pure bending zone. The stud numbers of HSC1-3 and HSC2- 4 were $2 n_{\text {stud }}$ and $1.5 n_{\text {stud }}$, respectively. HSC1- 4 used a partial composite connection, with a stud number of $0.25 n_{\text {stud. }}$. The studs and faceplate were connected by carbon-dioxide arc welding. Welding quality was tested by manual knocking, as shown in Figure 3.

2.2. Materials. The bottom steel faceplates were Q235B, and steel bars and shear reinforcements were HPB300. The studs were hexagon bolts with a strength grade of 4.8 , which means that the ultimate tensile strength is $400 \mathrm{MPa}$ and the yield ratio is 0.8 . The yield and ultimate strengths of the steel faceplates, studs, tie bars, and longitudinal steel bars were obtained from coupon tensile tests. Concrete cubes of $150 \mathrm{~mm}^{3}$ and prisms of $150 \mathrm{~mm} \times 150 \mathrm{~mm} \times 300 \mathrm{~mm}$ were prepared and tested on the same day of the slabs to measure the strength and elastic 

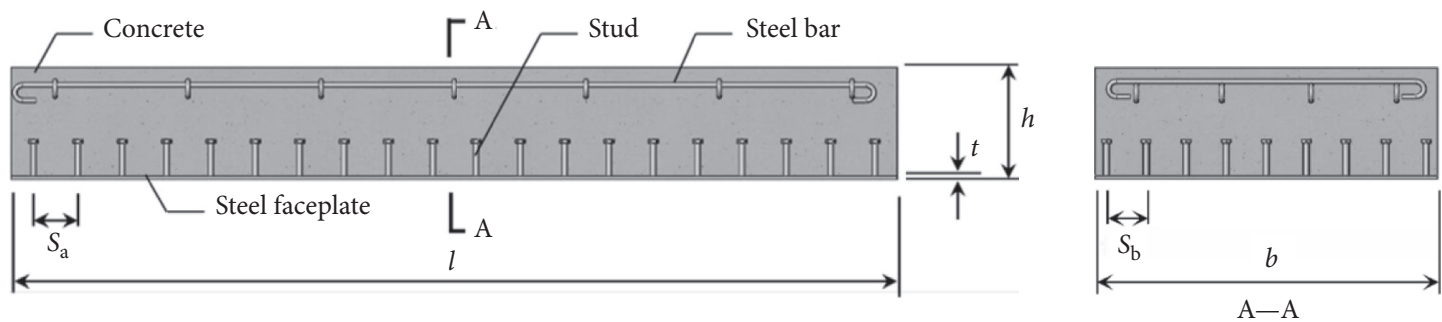

(a)
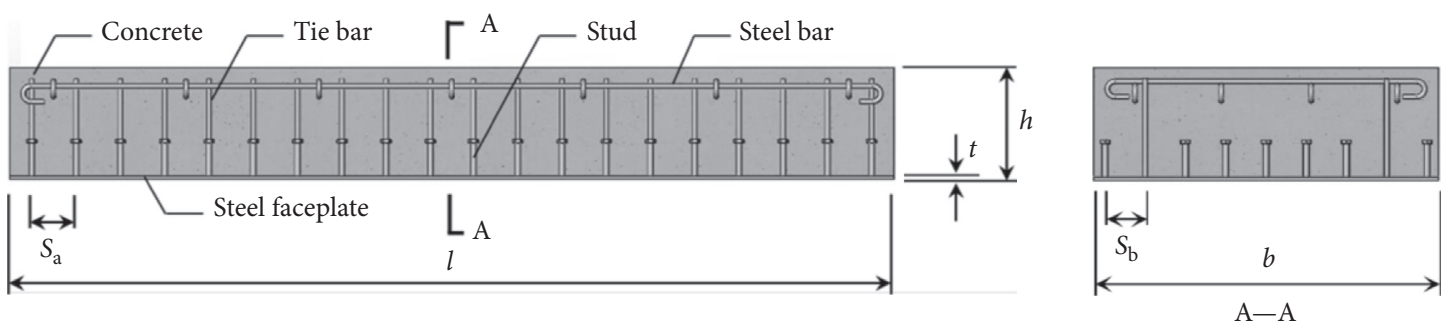

(b)
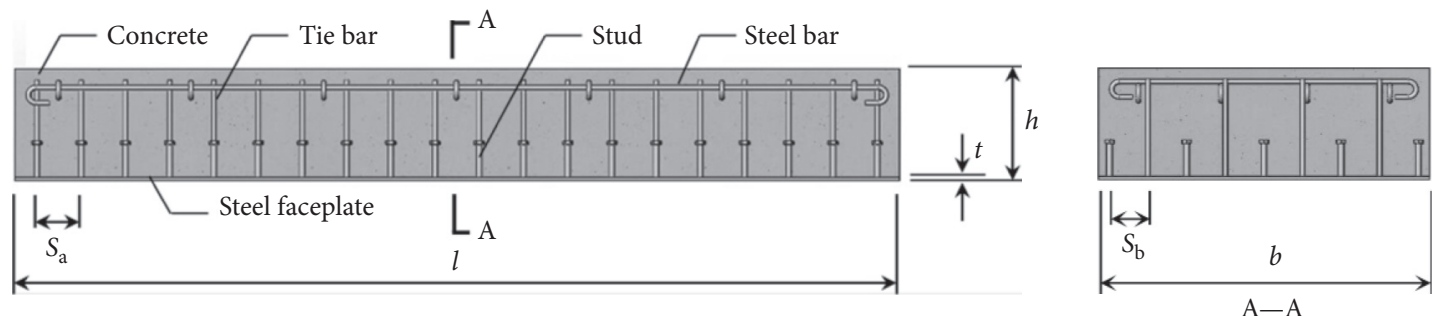

(c)

Figure 2: Section detail drawings: (a) Section 1 (except HSC2-7 and HSC2-8); (b) Section 2 (for HSC2-7); (c) Section 3 (for HSC2-8).

TABLE 1: Design parameters of the specimens.

\begin{tabular}{|c|c|c|c|c|c|c|c|c|c|c|c|}
\hline Specimen & $l(\mathrm{~mm})$ & $b(\mathrm{~mm})$ & $h(\mathrm{~mm})$ & $t(\mathrm{~mm})$ & $S_{\mathrm{a}}$ & $S_{\mathrm{b}}$ & $B_{\mathrm{L}}$ & $B_{\mathrm{TS}}$ & $B_{\mathrm{TI}}$ & Figure & $\lambda$ \\
\hline HSC1-1 & 2000 & 600 & 100 & 1.80 & M6@80 & M6@65 & Ф6@150 & Ф6@240 & - & Figure 2(a) & 6.0 \\
\hline HSC1-2 & 2000 & 600 & 100 & 1.80 & M6@80 & M6@65 & Ф6@150 & Ф6@240 & - & Figure 2(a) & 6.0 \\
\hline HSC1-3 & 2000 & 600 & 100 & 1.80 & M6@50 & M6@50 & Ф6@150 & Ф6@240 & - & Figure 2(a) & 6.0 \\
\hline HSC1-4 & 2000 & 600 & 100 & 1.80 & M6@160 & M6@130 & Ф6@150 & Ф6@240 & - & Figure $2(a)$ & 6.0 \\
\hline HSC1-5 & 2000 & 600 & 100 & 3.72 & M10@90 & M10@80 & Ф6@150 & Ф6@240 & - & Figure 2(a) & 6.0 \\
\hline HSC2-1 & 2000 & 600 & 200 & 3.72 & M10@100 & M10@90 & Ф8@150 & Ф8@240 & - & Figure 2(a) & 4.5 \\
\hline HSC2-2 & 2000 & 600 & 200 & 3.72 & M10@90 & M10@80 & Ф8@150 & Ф8@240 & - & Figure 2(a) & 3.0 \\
\hline HSC2-3 & 1600 & 600 & 200 & 3.72 & M10@80 & M10@70 & Ф8@150 & Ф8@240 & - & Figure $2(a)$ & 2.0 \\
\hline HSC2-4 & 1600 & 600 & 200 & 3.72 & M10@60 & M10@60 & Ф8@150 & Ф8@240 & - & Figure $2(a)$ & 2.0 \\
\hline HSC2-5 & 1600 & 600 & 200 & 1.80 & M6@65 & M6@60 & Ф8@150 & Ф8@240 & - & Figure $2(a)$ & 2.0 \\
\hline HSC2-6 & 1600 & 600 & 200 & 3.72 & M10@80 & M10@70 & Ф8@150 & Ф8@240 & - & Figure $2(a)$ & 2.0 \\
\hline HSC2-7 & 1600 & 600 & 200 & 3.72 & M10@80 & M10@70 & Ф8@150 & Ф8@240 & 2Ф8@80 & Figure 2(b) & 2.0 \\
\hline HSC2-8 & 1600 & 600 & 200 & 3.72 & M10@80 & M10@70 & Ф8@150 & Ф8@240 & 4Ф8@80 & Figure $2(\mathrm{c})$ & 2.0 \\
\hline HSC2-9 & 1400 & 600 & 200 & 3.72 & M10@70 & M10@60 & Ф8@150 & Ф8@240 & - & Figure 2(a) & 1.5 \\
\hline HSC2-10 & 1200 & 600 & 200 & 3.72 & M10@55 & M10@60 & Ф8@150 & Ф8@240 & - & Figure 2(a) & 1.0 \\
\hline
\end{tabular}

Note. (1) Shear span ratio $\lambda$ refers to the ratio of the length from the loading point to the support point and the section depth. (2) $B_{\mathrm{L}}$ is the configuration of a longitudinal steel bar on the top of concrete. (3) $B_{\mathrm{TS}}$ is the configuration of the transverse steel bar on the top of concrete. (4) $B_{\mathrm{TI}}$ is the configuration of the tie bar in concrete.

modulus of concrete, respectively, according to the Chinese standard GB50010-2010 [12]. Material properties of steel and concrete are summarized in Table 2.
2.3. Test Set-Up. The test device is shown in Figure 4. All slabs were simply supported at two ends. For group I, all the five Half-SC slabs were subjected to four-point 


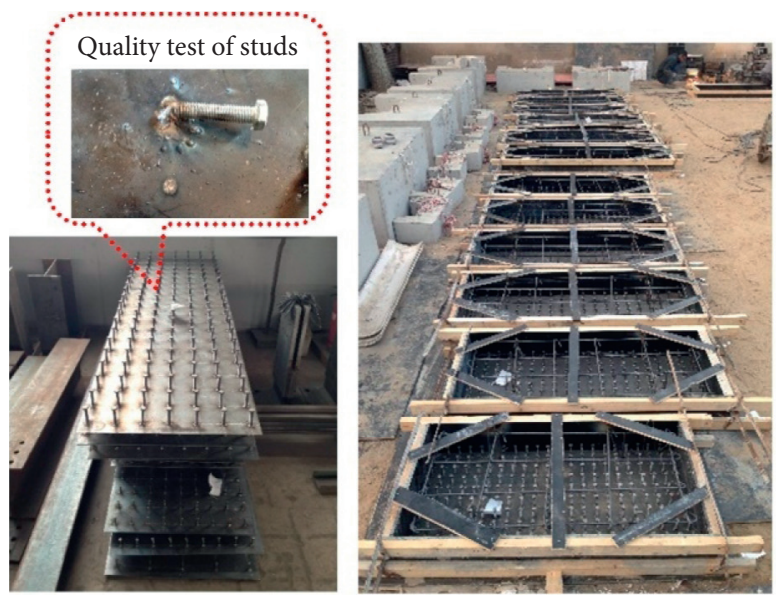

Before casting

Step 1 preparing of steel skeletons

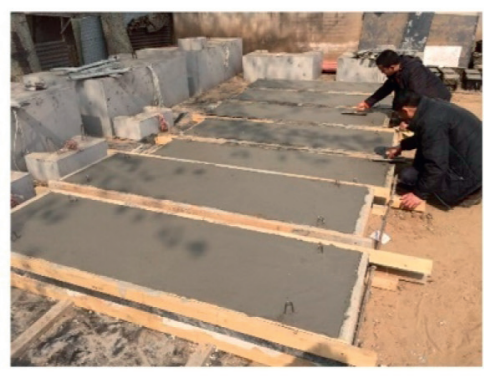

Casting

Step 1 casting of Half-SC slabs

Figure 3: Details and fabrication of Half-SC slabs.

TABLE 2: Material properties of concrete and steel $\left(\mathrm{N} / \mathrm{mm}^{2}\right.$, mean value).

\begin{tabular}{lcccccccrrr}
\hline Specimen & $f_{\mathrm{cu}}$ & $E_{\mathrm{c}} / 10^{4}$ & $f_{\mathrm{yp}}$ & $f_{\mathrm{up}}$ & $E_{\mathrm{p}} / 10^{5}$ & $f_{\mathrm{y}, \text { stud }}$ & $f_{\mathrm{u}, \text { stud }}$ & $f_{\mathrm{y}}$ & $f_{\mathrm{u}}$ & $E_{\mathrm{s}} / 10^{5}$ \\
\hline HSC1-1 HSC1-4 & 61.77 & 3.15 & 431.32 & 558.86 & 2.16 & 340 & 450 & 324.09 & 456.77 & 2.08 \\
HSC1-5 & 61.77 & 3.15 & 322.51 & 423.12 & 2.12 & 345 & 455 & 324.09 & 456.77 & 2.08 \\
HSC2-1 HSC2-4 & 61.77 & 3.15 & 366.40 & 535.54 & 2.12 & 345 & 455 & 295.88 & 403.48 & 2.16 \\
HSC2-5 & 61.77 & 3.15 & 431.32 & 558.86 & 2.16 & 340 & 450 & 295.88 & 403.48 & 2.16 \\
HSC2-6 HSC2-10 & 61.77 & 3.15 & 366.40 & 535.54 & 2.12 & 345 & 455 & 295.88 & 403.48 & 2.16 \\
\hline
\end{tabular}

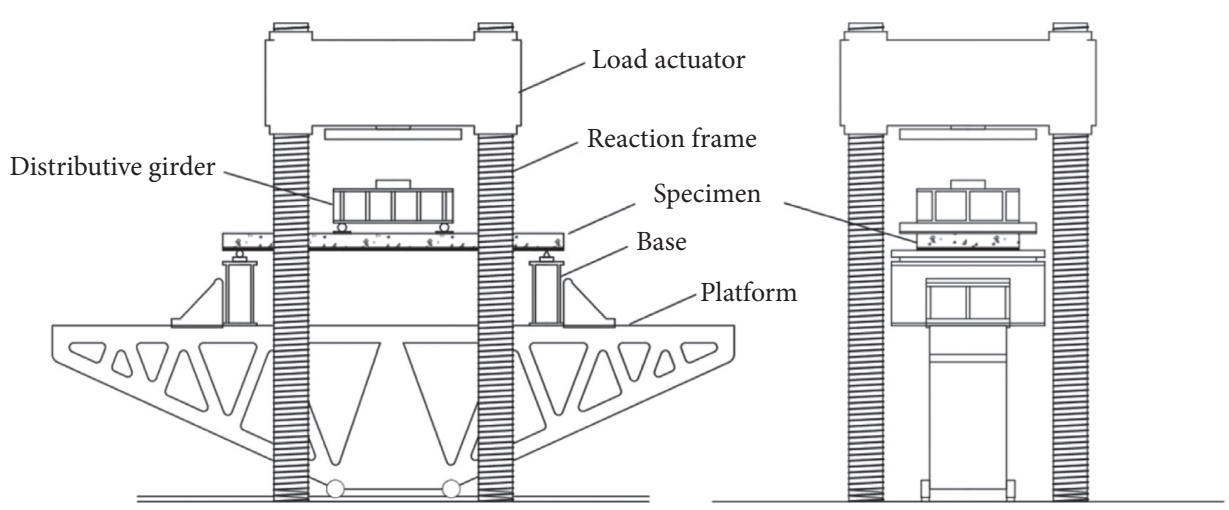

Figure 4: Test device.

loading, where the length of the pure bending zone was $600 \mathrm{~mm}$. The length of the shear-compression zone was $600 \mathrm{~mm}$ and $\lambda$ (shear span ratio) was 6 . For group II, all specimens were tested under four-point loading, where the pure bending zone was $600 \mathrm{~mm}$, and $\lambda$ was changed by varying the shear span length as shown in Figure 5 . The only exception was HSC2-1, which was tested under threepoint loading with a $\lambda$ of 4.5 .

2.4. Instrumentation. The arrangement details of strain gauges and displacement sensors are shown in Figure 6. In order to verify the plane section assumption, 3 to 4 resistance strain gauges with a length of $100 \mathrm{~mm}$ were bonded to one side of the specimen.

Two dial gauges (DG1-2) were installed at both ends of the specimens, where the magnetic pedestal was fixed to the steel faceplate and the pointer was attached to the bottom of concrete, as shown in Figure 7. Using this method, the total relative slippage between steel faceplate and concrete could be measured. Longitudinal grid lines with $200 \mathrm{~mm}$ intervals were drawn in the middle of every specimen to observe concrete cracks more easily. All the strain and displacement data were recorded by dynamic strain indicator and the sampling frequency was $2000 \mathrm{~Hz}$. 


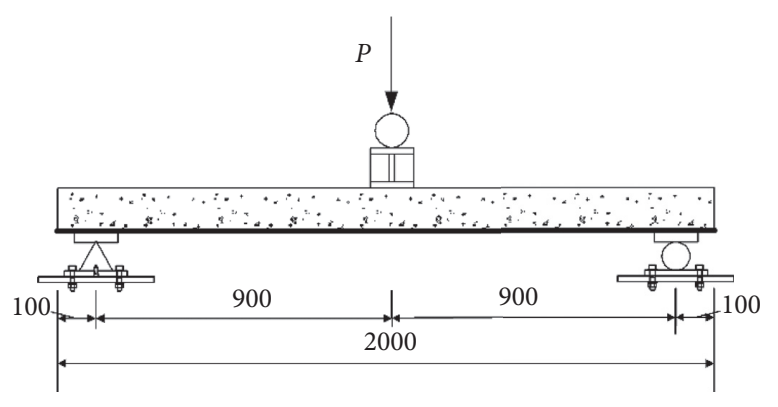

(a)

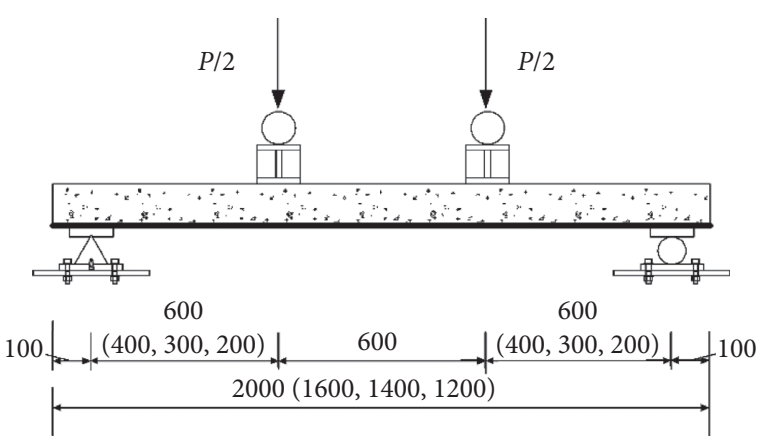

(b)

FIGURE 5: Loading configurations for tested specimens (unit: mm). (a) HSC2-1. (b) HSC1-1 HSC1-5, and HSC2-2 HSC2-10.
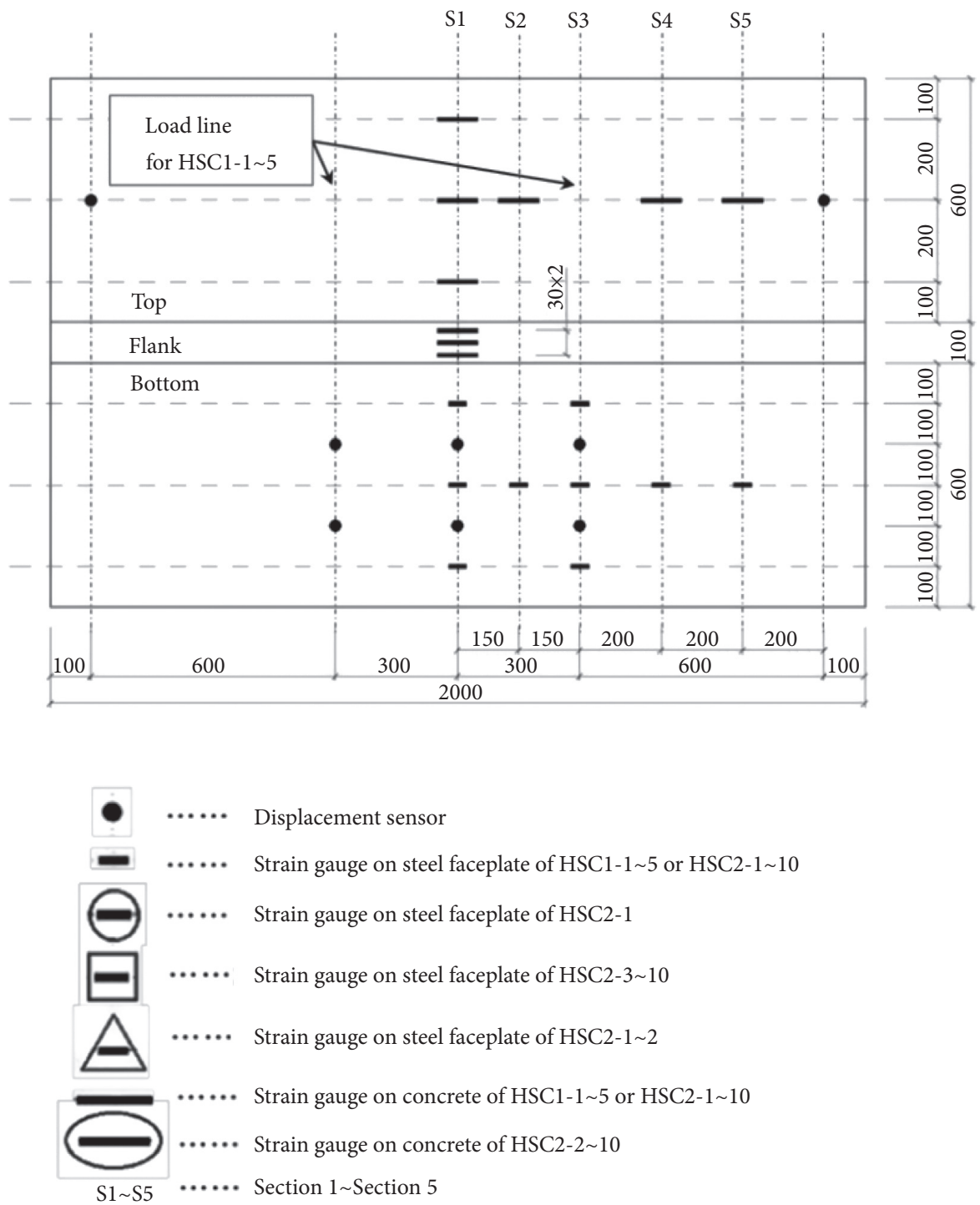

(a)

Figure 6: Continued. 

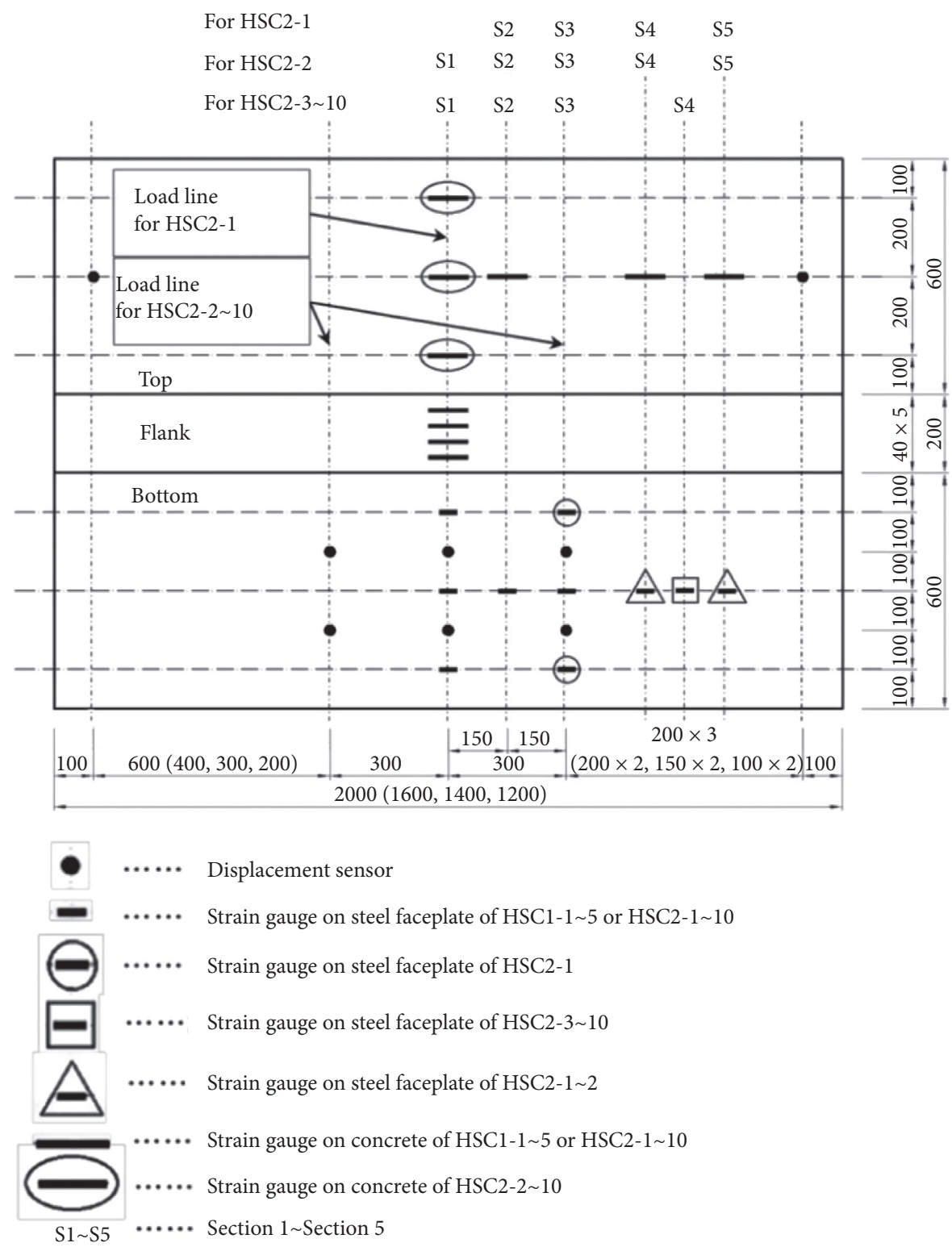

(b)

Figure 6: Measuring scheme(unit: mm). (a) Group I. (b) Group II.
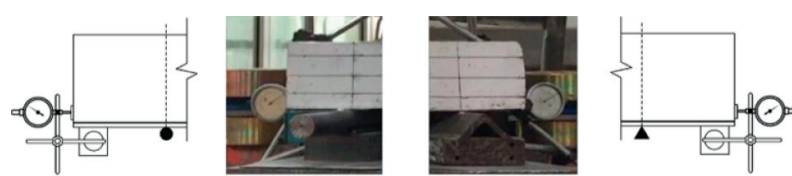

Figure 7: Dial gauges to test the slippage between faceplate and concrete.

\section{Results and Discussions}

\subsection{General Behavior and Failure Modes}

3.1.1. Flexural Failure. The flexural failures of specimens (HSC1-1, HSC1-2, HSC1-3, and HSC1-5) are shown in Figure 8. Taking the specimen HSC1-1 as an example, the process of crack propagation is shown in Figure 9, which indicates that the flexural failure of Half-SC slabs is similar to that of reinforced concrete members, i.e., vertical cracks in pure bending zone fully developed followed by concrete crushing.

Load versus midspan deflection curves of specimens with flexural failure are shown in Figure 10. Specimens HSC1-1 and HSC1-2 are control specimens with the same design and loading conditions. By using Saichi and Shinohe's method [13], the load versus midspan deflection curves are processed by averaging and then named as Avg (HSC1-1, 1-2). Contrasting with the load versus midspan deflection curves of HSC1-5 and Avg (HSC1-1, 1-2) in Figure 10, with the increase of the steel faceplate thickness, the failure mode will change from balanced-reinforced failure to over-reinforced failure, which means that the 


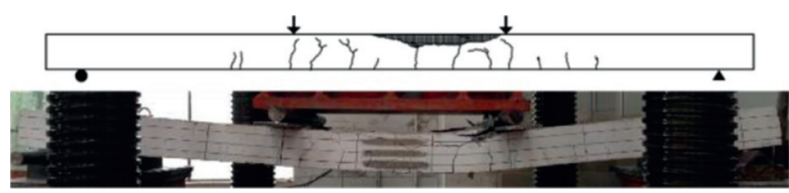

(a)

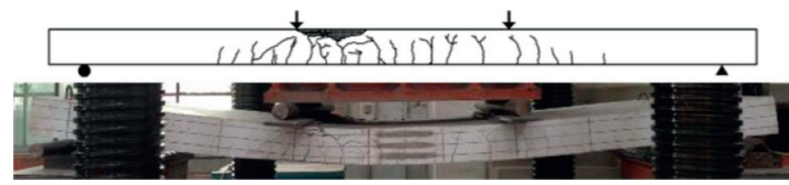

(c)

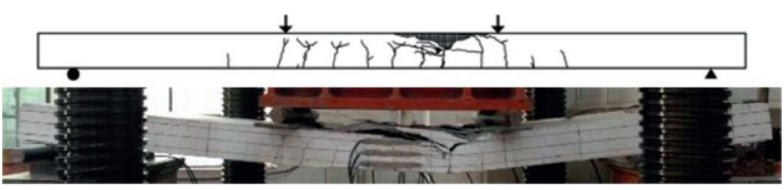

(b)

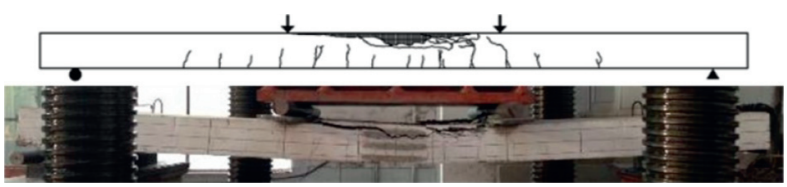

(d)

Figure 8: Deformation and crack distribution in flexural failing specimens: (a) HSC1-1; (b) HSC1-2; (c) HSC1-3; (d) HSC1-5.

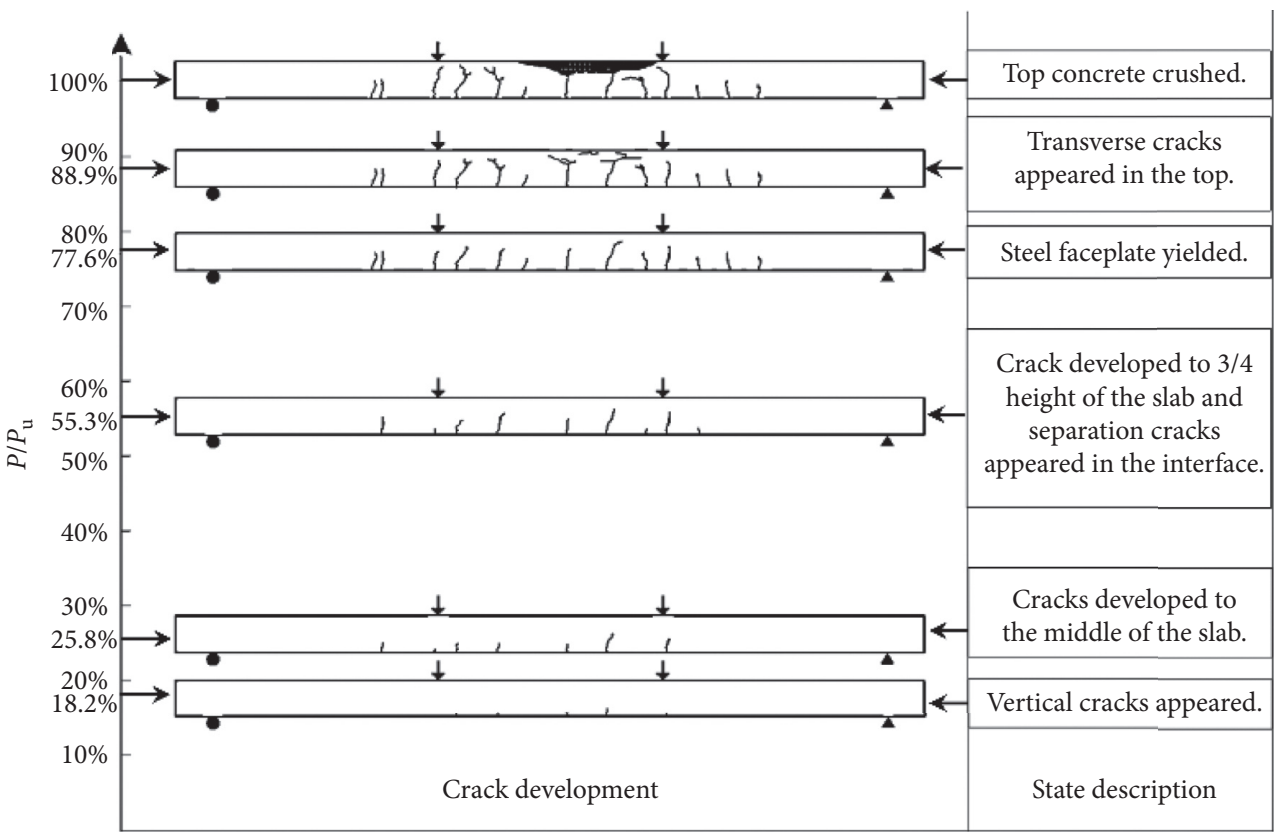

FIgURE 9: Description of the failure process of HSC1-1.

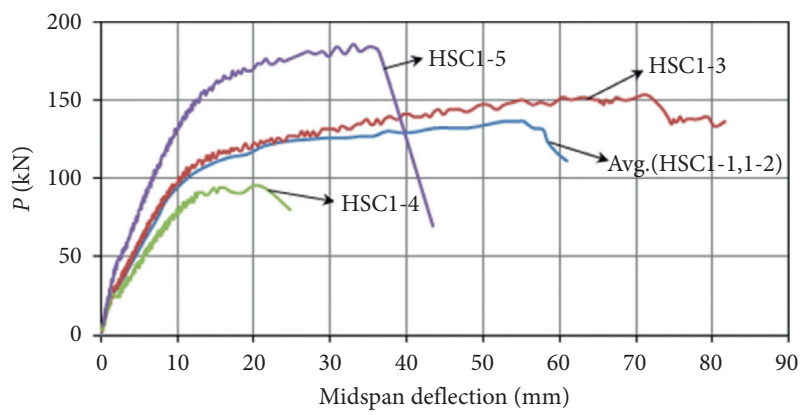

FIgURE 10: Load versus midspan deflection curves.

failure of specimen will gradually change from ductile to brittle. Compared with the significant increase in the number of studs, the increase of ultimate strength was negligible. If the number of studs reduced to $25 \%$ of that in Avg (HSC1-1, 1-2), the failure mode of Half-SC slabs changed from flexural to interface slippage, and the ultimate strength and ductility coefficient reduced significantly by $11.9 \%$ and $28.7 \%$, respectively. The plastic development of the specimen was inadequate, which caused the failure to change from ductile to brittle.

3.1.2. Interface Slippage Failure. The failure mode of HSC1-4 is shown in Figure 11. The crack propagation of this specimen was similar to that of the specimen that failed from flexure at the initial stage of loading. When the load was about $0.3 P_{\mathrm{u}}$, the vertical crack below the loading point had crossed the middle surface of the slab, and the readings of dial gauges at both ends of the specimen became larger. When the load was about $0.5 P_{\mathrm{u}}$, the vertical and diagonal cracks on the interface developed rapidly. When the load was close to $P_{\mathrm{u}}$, the readings of dial gauges at both ends of the specimen were over $1 \mathrm{~mm}$, and the increase of midspan deflection was obvious. When the load was slightly over $P_{\mathrm{u}}$, the concrete of the specimen abruptly broke along the diagonal crack, and the studs around the concrete fracture 


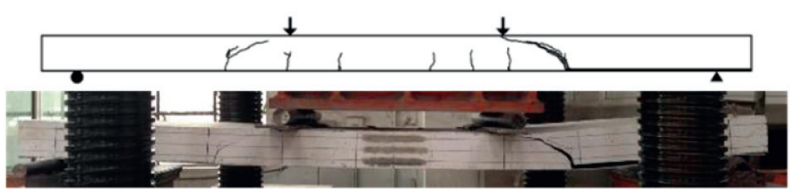

FIGURE 11: Deformation and crack distribution in HSC1-4.

were broken by shear force. Meanwhile, the specimen broke due to the separation of concrete and steel faceplate.

3.1.3. Shear Failure. Except for HSC2-8, the failure modes of all other nine specimens were a shear failure as shown in Figure 12. The crack propagation of specimen HSC2-6 is shown in Figure 13, which indicates that the shear failure of the Half-SC slab began with tensile cracking in pure bending zone, followed by $45^{\circ}$ diagonal cracks at the loading point, similar to the reinforced concrete slab. At the critical point, a critical diagonal crack appeared penetrating through the loading point and support. The load versus midspan deflection curves of the shear failure specimens are shown in Figure 14. HSC2-3 and HSC2-6 were control specimens with the same design and loading condition. Using Saichi and Shinohe's method [13], load versus midspan deflection curves were averaged and named as Avg (HSC2-3, 2-6). The steel faceplate thickness of HSC2-5 was $48.4 \%$ of that of Avg (HSC2-3, 2-6), and the ultimate strength of HSC2-5 had a significant decrease of $67.3 \%$. For Avg (HSC2-3, 2-6), the main diagonal cracks penetrated the concrete from the loading point to support, which caused the specimen failure. For HSC2-5, the main diagonal cracks penetrated the concrete from the loading point but did not reach the support, and a row of studs at the bottom of the crack was pulled off. The steel faceplate yielded obviously. The bottom plate plays a significant role in shear failure owing to the membrane action. The concrete and steel faceplate have different contributions to the shear capacity of the specimen, and the failure mode depends on which of the two contributes most to shear capacity.

The number of studs in HSC2-4 was $150 \%$ of that in Avg (HSC2-3, 2-6). As shown in Figure 14, with the increase of the number of studs, the yield strength and ultimate strength of Half-SC slabs improved by $7.1 \%$ and $12.9 \%$, respectively, and the ductility coefficient improved by $13.7 \%$. It means that when the studs exactly met the requirements of full composite connection, the increase of the number of studs could still improve the deformation capability of Half-SC slabs and have a positive effect on the shear load-bearing capacity. However, these changes are inconspicuous compared with the significant increase in the number of studs.

The shear span ratios of HSC2-1, HSC2-2, Avg (HSC2-3, 2-6), HSC2-9, and HSC2-10 were 4.5, 3, 2, 1.5, and 1, respectively. As shown in Figure 14, when the shear span ratio $\lambda>1.5$, with the reduction of the shear span ratio, the ultimate strength increased obviously and all the ductility coefficients were more than 4 . When the shear span ratio $\lambda \leq 1.5$, with the reduction of the shear span ratio, the ultimate strength is basically unchanged and the ductility coefficient decreased obviously. Furthermore, the failure changed from ductile to brittle.

The volumetric ratio of tie bars is defined as $\rho_{\mathrm{sv}}$. For Avg (HSC2-3, 2-6), HSC2-7, and HSC2-8, $\rho_{\mathrm{sv}}=0 \%$, $0.21 \%$, and $0.42 \%$, respectively. As shown in Figure 14, with the increase of $\rho_{\mathrm{sv}}$, the ultimate strength of HSC2-7 and HSC2-8 increased by $6.6 \%$ and $8.2 \%$, respectively, and the ductility coefficient increased by $17.4 \%$ and $23.2 \%$, respectively. The failure mode of HSC2-8 was a balanced failure, which means that the increases of the volume tie bar ratio could postpone the occurrence of shear failure and even converted the failure mode gradually to flexural.

3.1.4. Balanced Failure. For specimen HSC2-8, the shear span ratio $\lambda$ was 2 and the ratio of tie bars was $0.42 \%$. During the loading process, crack development and failure process were similar to those of specimen HSC2-3. After $30^{\circ}$ diagonal cracks appeared, the critical diagonal crack was formed across the section between the loading point and support in the loading process. Meanwhile, the concrete in the top of the pure bending zone was crushed and the load-bearing capacity of the specimen was lost. It can be seen that the failure includes both flexural and shearing failure characteristics, which can be defined as balanced failure. The failure mode of the specimen is shown in Figure 15.

\subsection{Strain Distribution}

3.2.1. Group I. Two failure modes were observed in group I. Except for specimen HSC1-4, where its failure mode was interface slippage, all the other four specimens were the flexural failure. Strain developments of steel faceplate and concrete in all four specimens had the same trend. The specimen HSC1-1 was taken as an example. The load and longitudinal strains of steel faceplate and concrete versus midspan deflection are shown in Figure 16. When the strain of steel at the pure bending zone reached the yield value, the load-deflection curve entered the yield stage. The strain of the steel faceplate in the shear-compression zone increased slowly and the steel faceplate in the shear-compression zone had not yielded even when the specimen broke.

Distributions of longitudinal strain at the midspan section of the five specimens in group I are shown in Figure 17. In the figure, the coordinate $y$ shows the position of strain along the height of the section; e.g., $y=-50$ and 50 denote the position of steel faceplate and top concrete, respectively. As shown in Figure 17, due to the cracking of concrete and the slip of the interface, the strain of the steel faceplate developed either earlier or later than that of the top concrete. HSC1-4 used partial composite connection, where studs yielded before the steel faceplate. When the load reached the yield load, the strain of the steel faceplate developed slightly later than that of the top concrete. However, the strain distribution of the section was also close to a straight line and the average strain of the section basically conformed to the plane section assumption. 


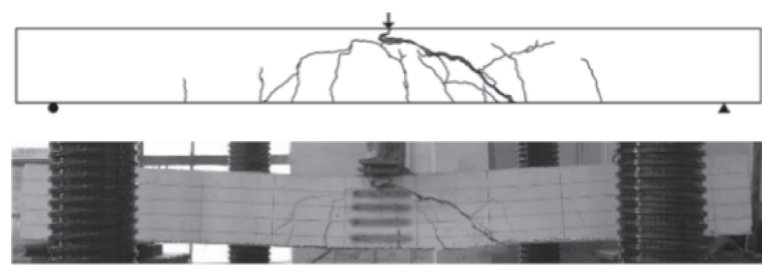

(a)

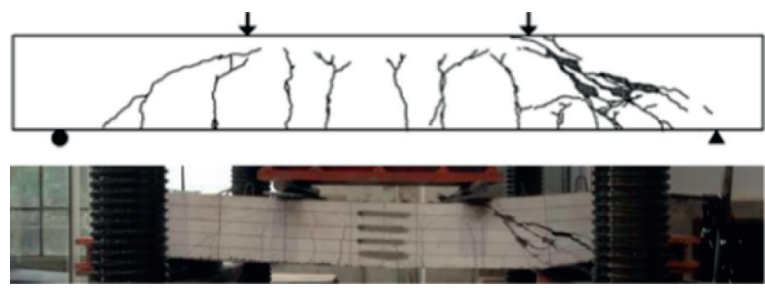

(c)
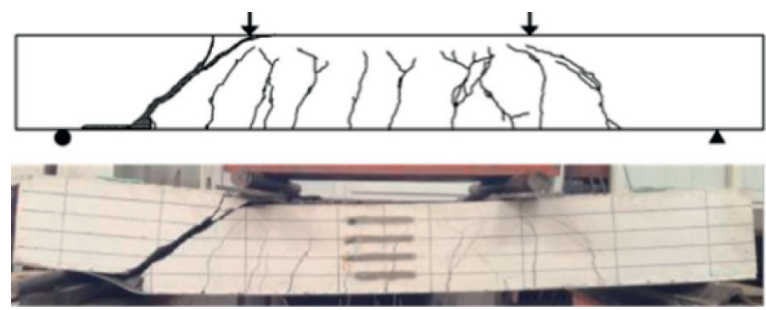

(e)

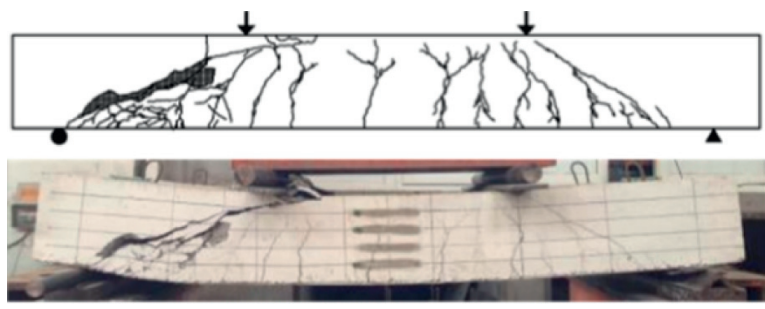

(g)

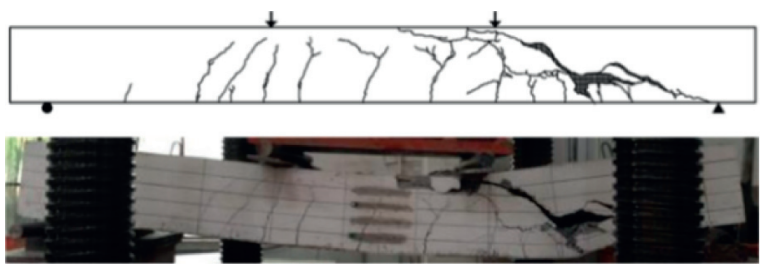

(b)

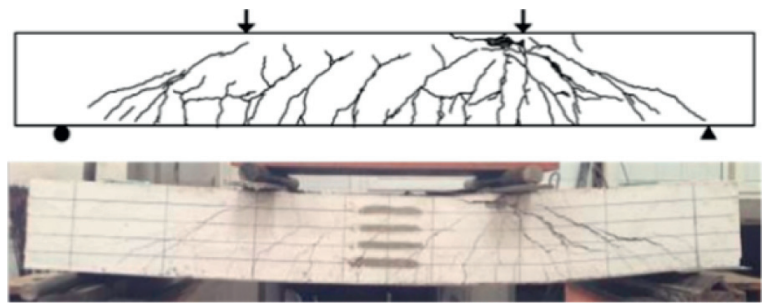

(d)
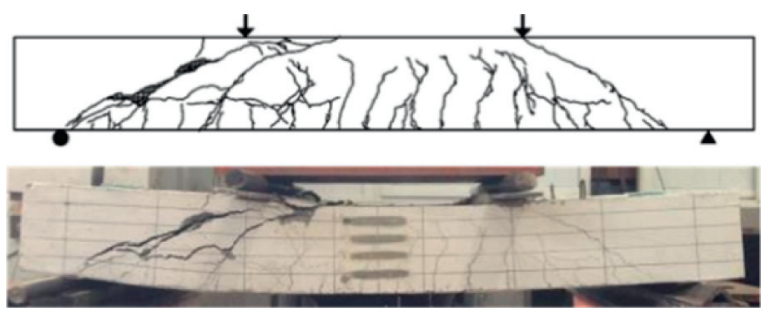

(f)

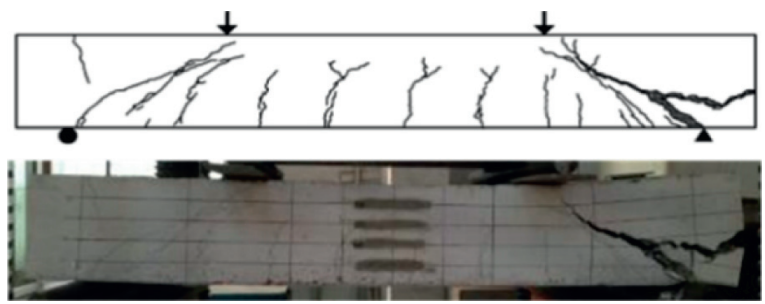

(h)
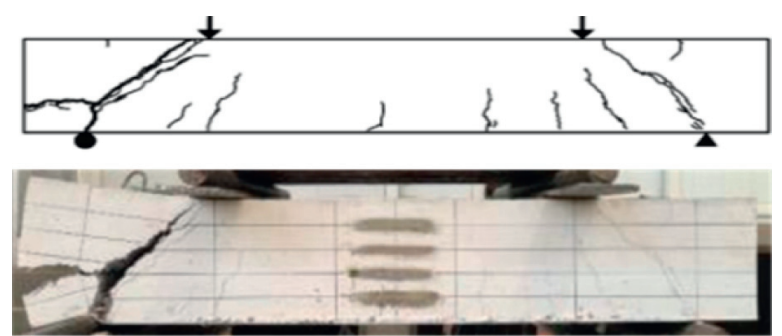

(i)

FIGURE 12: Deformation and crack distribution in shear failing specimens: (a) HSC2-1; (b) HSC2-2; (c) HSC2-3; (d) HSC2-4; (e) HSC2-5; (f) HSC2-6; (g) HSC2-7; (h) HSC2-9; (i) HSC2-10.

3.2.2. Group II. The main failure mode of the specimens in group II was a shear failure, and the specimen HSC2-3 was taken as an example to illustrate. The load and longitudinal strains of the steel faceplate and concrete as a function of midspan deflection are shown in Figure 18. From sections 1 and 2, it can be seen that the failure process of HSC2-3 was similar to that of HSC1-1, which was a flexural failure. With the increase of load, the local yield occurred first in the pure bending zone of steel faceplate, and then all the sections in the pure bending zone yielded indicating that the specimen has entered the yield stage.

From sections 3 and 4 , it can be seen that the failure process of specimen HSC2-3 was quite different from HSC11 which was in flexural failure. The steel faceplate strain development of HSC2-3 was obviously larger than that of HSC1-1. And shortly after the load reached the yield load, the steel faceplate in the middle of the shear-compression zone (section 4) yielded. Therefore, for the Half-SC 


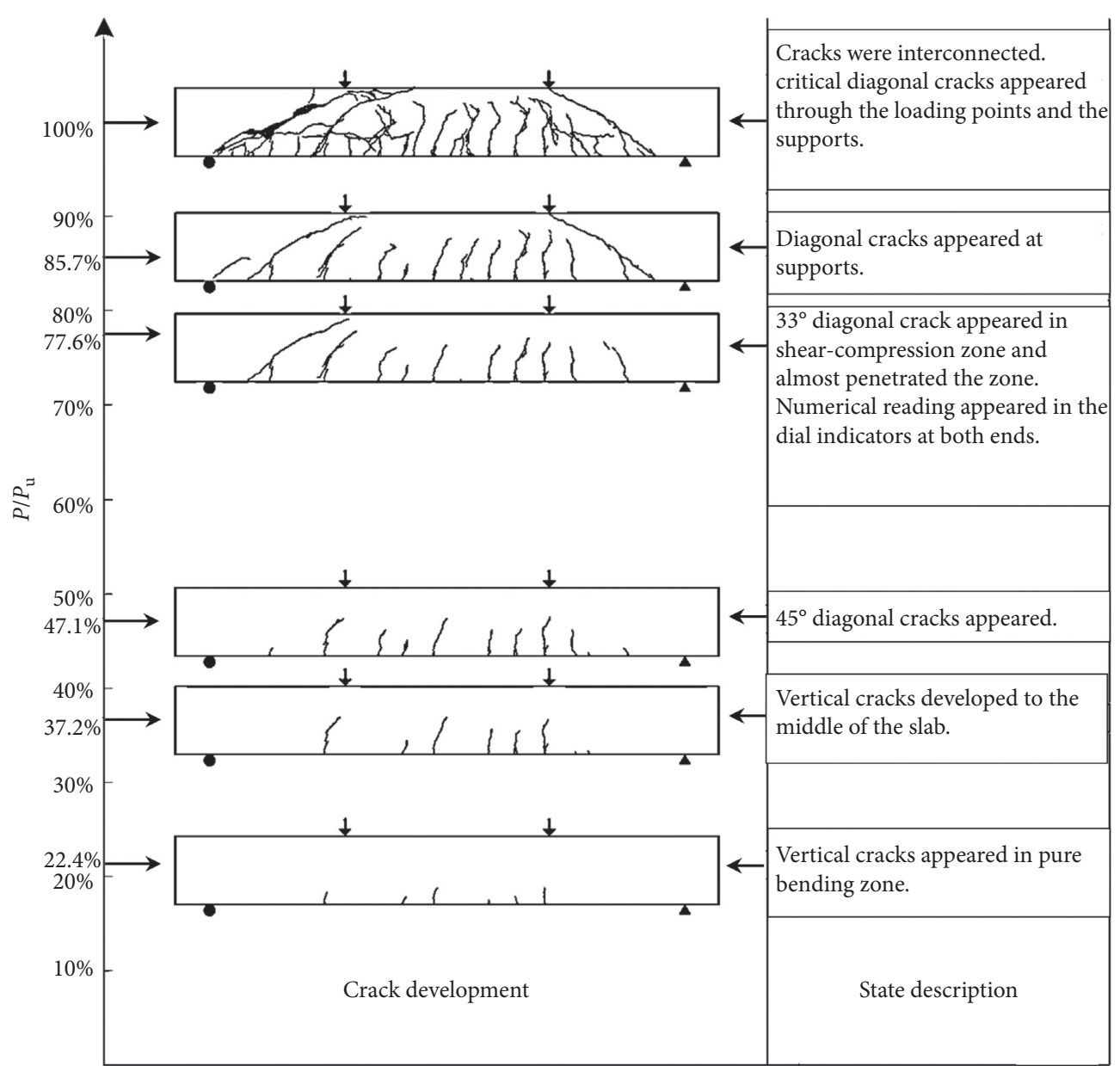

Figure 13: Description of the failure process of HSC2-6.

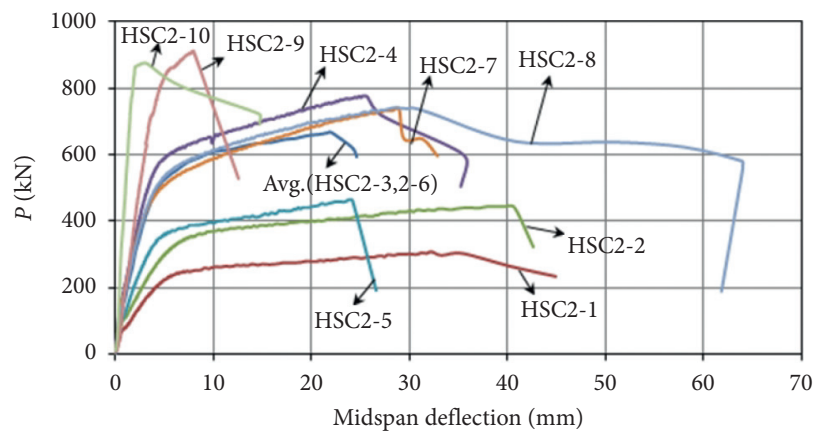

Figure 14: Load versus midspan deflection curves.

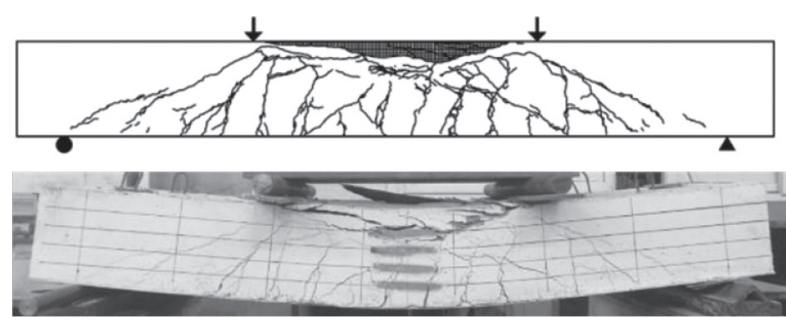

Figure 15: Deformation and crack distribution in HSC2-8. specimen with shear failure, the steel faceplate in the shearcompression zone probably yielded. However, because of the low shear span ratio of the specimen HSC2-10, the steel faceplate in the middle of the shear-compression zone did not yield. It indicates that the shear-compression zone of the steel faceplate could achieve yield strength and had a significant effect on the shear strength of the specimen, which was different from the performance of the longitudinal reinforcement in reinforced concrete slabs with shear failure. 


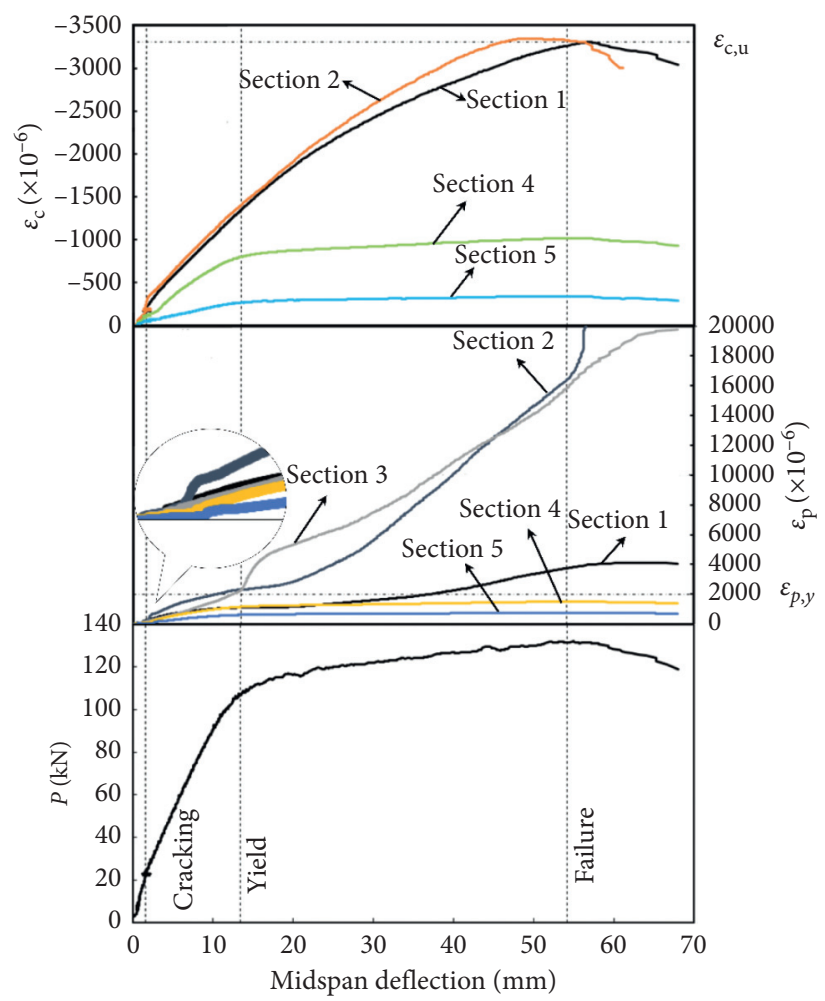

FIGURE 16: Load $(P)$ and the longitudinal strain of concrete $\left(\varepsilon_{\mathrm{c}}\right)$ as well as steel faceplate $\left(\varepsilon_{\mathrm{p}}\right)$ versus midspan deflection curves for HSC1-1.

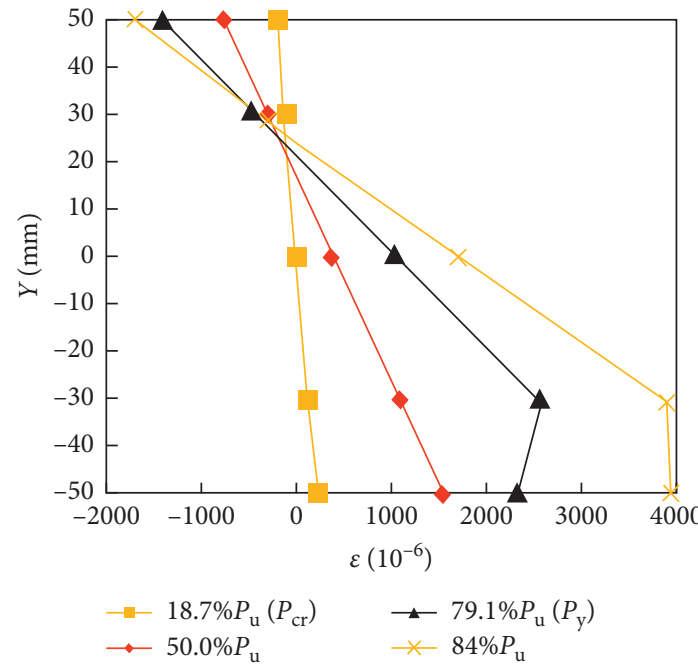

(a)

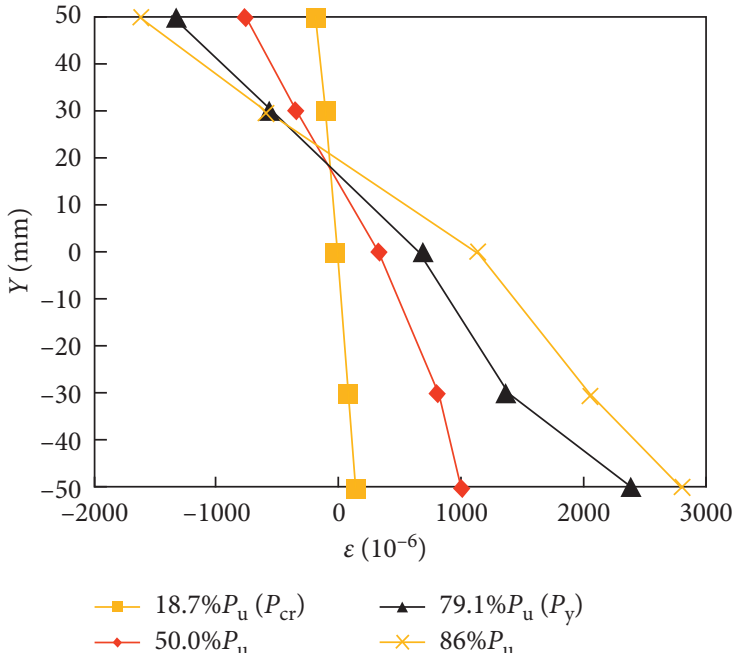

(b)

FIgURE 17: Continued. 


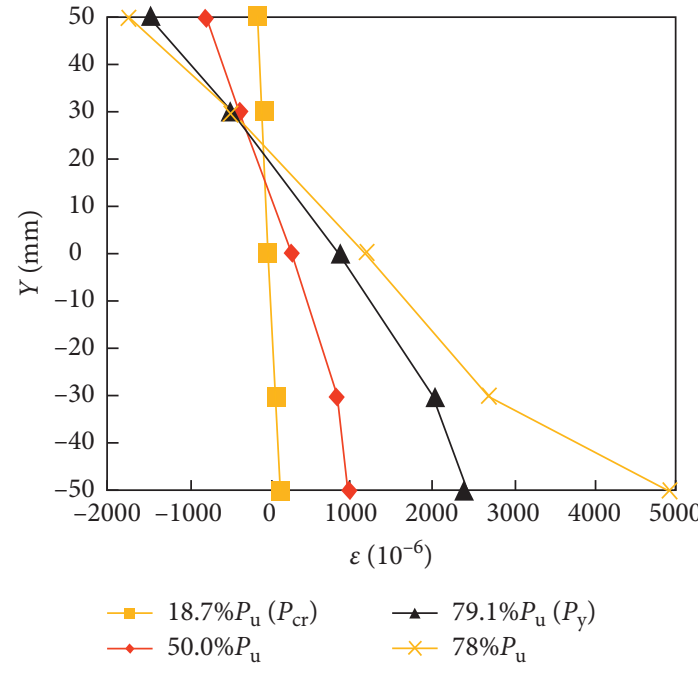

(c)

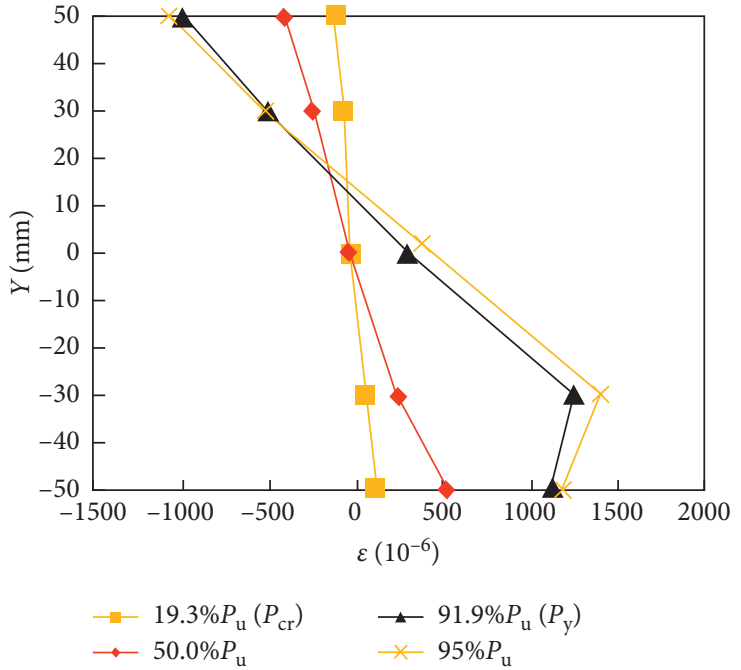

(d)

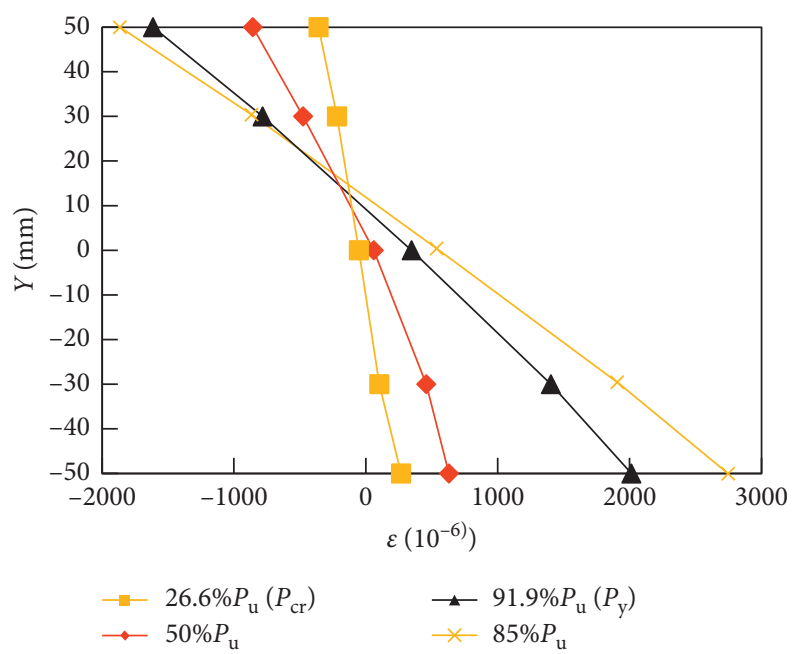

(e)

FIGURe 17: Distribution of longitudinal strain on midspan section: (a) HSC1-1; (b) HSC1-2; (c) HSC1-3; (d) HSC1-4; (e) HSC1-5.

\section{Out-of-Plane Flexural and Shear Strength}

4.1. Flexural Strength Calculating. From the test results, Half-SC slabs that have reinforcements on both tension and compression sides are similar to the concrete beams with compression steel. Chinese code GB50010 [12] for RC members is used to design and calculate the out-of-plane flexural strength of RC members. Based on section force equilibrium, the resulting equations for calculating the flexural strength $\left(M_{\mathrm{u}}\right)$ can be obtained as follows:

$$
\begin{aligned}
M_{\mathrm{u}} & =0.8 f_{\mathrm{c}} b x\left(h-\frac{t}{2}-\frac{x}{2}\right)+f_{\mathrm{y}} A_{\mathrm{s}}\left(h-a^{\prime}-\frac{t}{2}\right), \\
0.8 f_{\mathrm{c}} b x+f_{\mathrm{y}} A_{\mathrm{s}} & =f_{\mathrm{yp}} t b,
\end{aligned}
$$

where $f_{\mathrm{c}}$ is the concrete compressive strength, $f_{\mathrm{y}}$ is the yield strength of reinforcement, $f_{\mathrm{yp}}$ is the yield strength of steel plate, $A_{\mathrm{s}}$ is the total area of reinforcement, $b$ is the width of slab section, $x$ is the height of concrete compression zone, $h$ is the height of slab section, $t$ is the thickness of steel plate, and $a^{\prime}$ is the distance between the reinforcement and the upper edge of the slab.

Figure 19 presents the comparison between experimental and calculated values of the flexural strength. Experimental data of Half-SC slabs (SCRCPS and S1J1) under flexural failure are from research [9]. The coefficients of variation (COVs) vary from 0.880 to 1.092 , with an average value of 1.001 .

4.2. Shear Strength Calculating. Analyzing the failure mechanism of group II, it can be seen that shear failure shows two different forms when studs meet the requirement of complete shear connection. (1) Critical diagonal cracks are formed, which cross the loading points and the support and develop fully. They denote the failure of the concrete strut bar. (2) When the steel faceplate is thin, the strain of the steel faceplate significantly exceeds its yield 


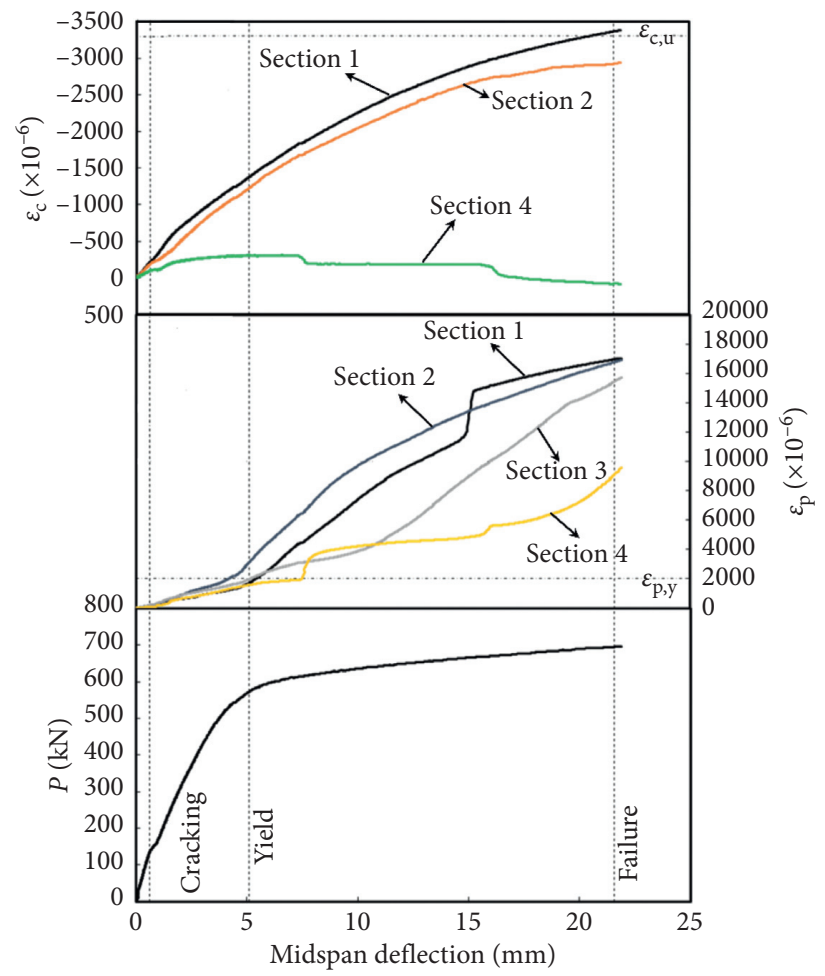

FIGURE 18: Load $(P)$ and the longitudinal strain of concrete $\left(\varepsilon_{\mathrm{c}}\right)$ as well as steel faceplate $\left(\varepsilon_{\mathrm{p}}\right)$ versus midspan deflection curves for HSC2-3.

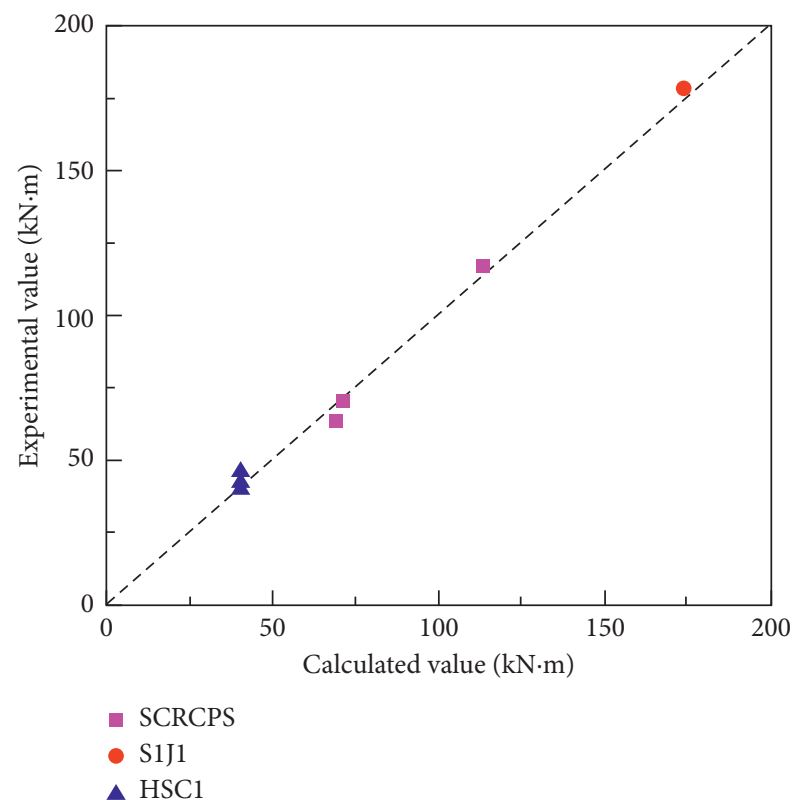

FIGURE 19: Experimental values and calculated values of flexural strength.

strain, which can cause faceplate breaking. The tie-arch model for shear failure can be proposed; i.e., the concrete strut bar is from the loading point to the support with a width of $v h$, and the steel faceplate takes tension force and constitutes the tie-arch in the shear-compression zone as shown in Figure 20(a).
In order to describe the splitting failure of the concrete strut bar, the force of the concrete strut bar is calculated as $\beta f_{\mathrm{t}} b h$, where $f_{\mathrm{t}}$ is the tensile strength of concrete. Support A is taken as an isolator and its stress is analyzed as shown in Figure 20(b).

Based on the equilibrium of forces,

$$
P_{\mathrm{u}}=\beta f_{\mathrm{t}} b h \cdot \frac{h}{\sqrt{\left(h^{2}+\lambda^{2} h^{2}\right)}}=\frac{\beta}{\sqrt{\left(1+\lambda^{2}\right)}} \cdot f_{\mathrm{t}} b h, \quad \Sigma Y=0 .
$$

By replacing $\beta / \sqrt{\left(1+\lambda^{2}\right)}$ with $a / \lambda$, where $a$ is an undetermined parameter, Equation (5) can be simplified as follow:

$$
P_{\mathrm{u}}=\frac{a}{\lambda} f_{\mathrm{t}} b h
$$

Fitting the result of nine specimens from this experiment is shown in Figure 21; these rules can be obtained. (1) When $1.5 \leq \lambda \leq 4.5, a=1.5$. (2) When $\lambda \leq 1.5, a / \lambda=1$.

Based on the equilibrium of the moment,

$$
\begin{aligned}
P_{\mathrm{u}} \cdot \lambda h & =f_{\mathrm{yp}} b t \cdot h, \quad \Sigma M_{\mathrm{C}}=0, \\
P_{\mathrm{u}} & =\frac{1}{\lambda} f_{\mathrm{yp}} b t .
\end{aligned}
$$

Tensile reinforcements are used as shear reinforcements, which can improve the strength of the concrete strut bar. Four of the existing 19 specimens have tensile reinforcements, whose enhancement is $0.25 f_{\mathrm{yv}} b h \rho_{\mathrm{sv}}$ after fitting. Here, $f_{\mathrm{yv}}$ is the tensile strength of shear reinforcement and 


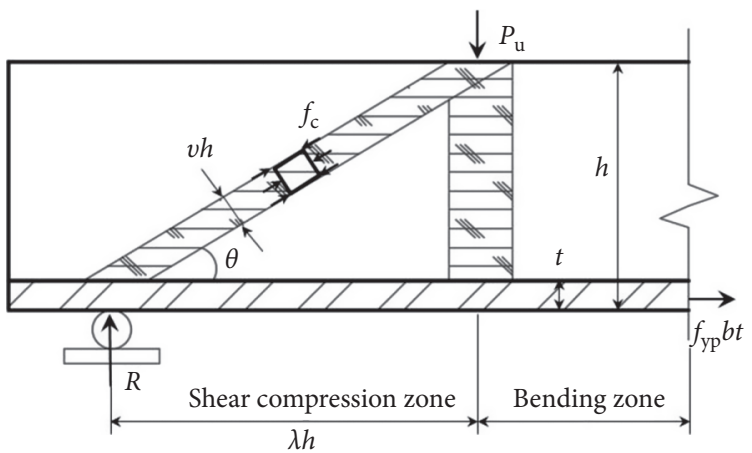

(a)

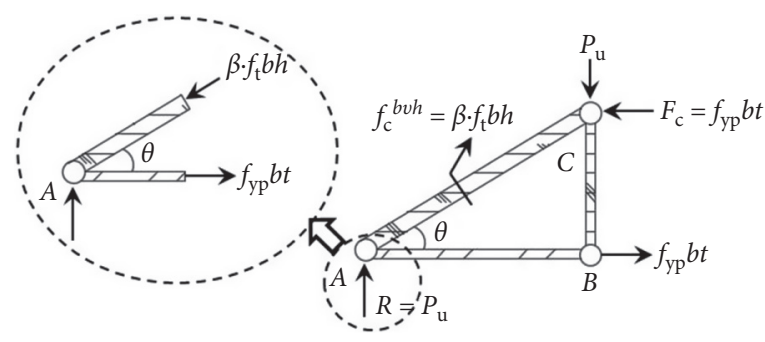

(b)

Figure 20: Tie-arch model: (a) stress analysis of Half-SC slab; (b) computing model.

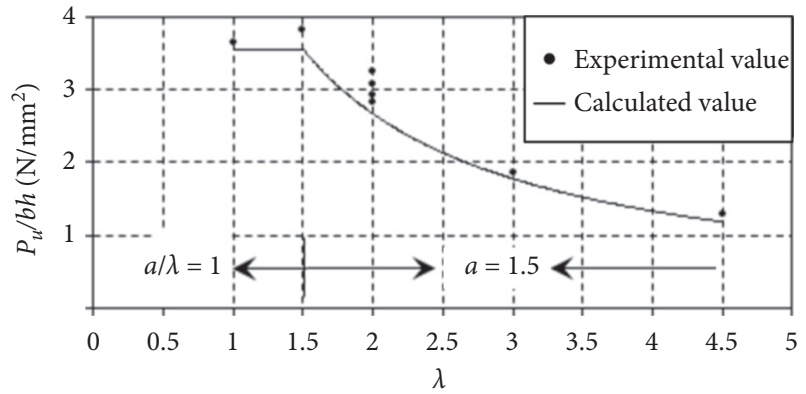

FIGURE 21: Fitting result of parameter $a$.

$\rho_{\mathrm{sv}}$ is the volume reinforcement ratio of shear reinforcement. The shear strength of Half-SC slabs can be expressed as

$$
\begin{aligned}
V_{\mathrm{u}} & =\min \left(V_{\mathrm{cv}}, V_{\mathrm{p}}\right), \\
V_{\mathrm{cv}} & =\frac{1.5}{\lambda} f_{\mathrm{t}} b h+0.25 f_{\mathrm{yv}} b h \rho_{\mathrm{sv}}, \\
V_{\mathrm{p}} & =\frac{1}{\lambda} f_{\mathrm{yp}} b t .
\end{aligned}
$$

Using equations (8)-(10), the 19 existing specimens are analyzed. The results, together with experimental results, are shown in Figure 22. Groups 11, 12, and $\mathrm{H}$ are specimens studied in [9]. The tensile strength of concrete $\left(f_{\mathrm{t}}\right)$ is calculated from the compressive strength of concrete cylinder $\left(f_{\mathrm{c}}^{\prime}\right)$ using $f_{\mathrm{c}}^{\prime}=0.79 f_{\mathrm{cu}}$ and $f_{\mathrm{t}}=0.395 f_{\mathrm{cu}}^{0.55}$, where $f_{\mathrm{cu}}$ is the cubic compressive strength of concrete. Group S1 are the specimens studied in [10] and group HSC2 are from this paper.

4.3. Transition of Flexural Failure and Shear Failure. For HSC2-8, concrete at the top of the pure bending zone was crushed when critical diagonal cracks crossed the shearcompression zone, which can be treated as a balanced failure, with features of both flexural strength and shear strength. HSC2-8 was checked separately using equations of flexural strength and shear strength. The results are shown in Table 3.

From Table 3, it can be seen that the calculated values from equations of flexural strength and shear strength are very close, which means that the flexural and shear failure

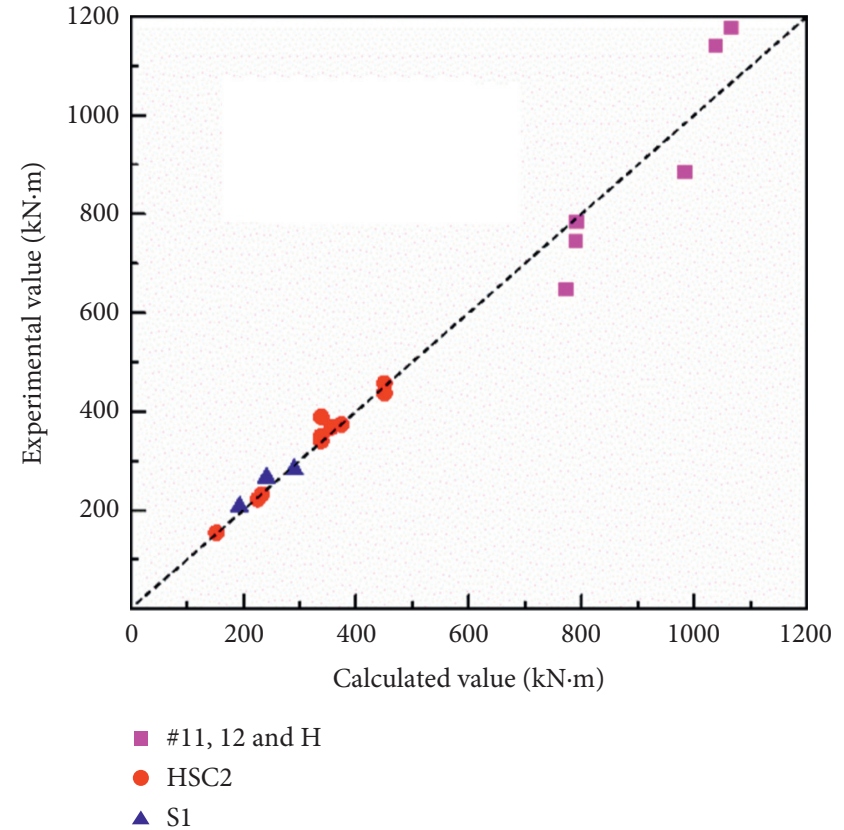

FIGURE 22: Experimental values and calculated values of shear strength.

TABLE 3: Comparison between the calculated values from equations of flexural strength $\left(F_{\mathrm{u}}\right)$ and shear strength $\left(V_{\mathrm{u}}\right)$.

\begin{tabular}{lccccc}
\hline Specimen & $F_{u}(\mathrm{kN})$ & $V_{\mathrm{u}}(\mathrm{kN})$ & $P_{\mathrm{u}}(\mathrm{kN})$ & $F_{\mathrm{u}} / P_{\mathrm{u}}$ & $V_{\mathrm{u}} / P_{\mathrm{u}}$ \\
\hline HSC2-8 & 752.00 & 712.66 & 745.74 & 1.008 & 0.956 \\
\hline
\end{tabular}

occurred simultaneously for HSC2-8. This phenomenon is consistent with what was obtained from the experiment. Compared with the results of HSC1-1, HSC1-2, HSC2-3, and HSC2-6, the failure mode of Half-SC slabs changes from flexural to shear with the decrease of shear span ratio or the increase of volumetric steel ratio of shear reinforcement. The failure mode depends on the minimum value between the flexural and shear strengths. When the shear strength is equal to the bending strength, the balanced failure occurs.

Based on HSC2-3 and considering the volumetric steel ratio of shear reinforcement, the variation of ultimate load 


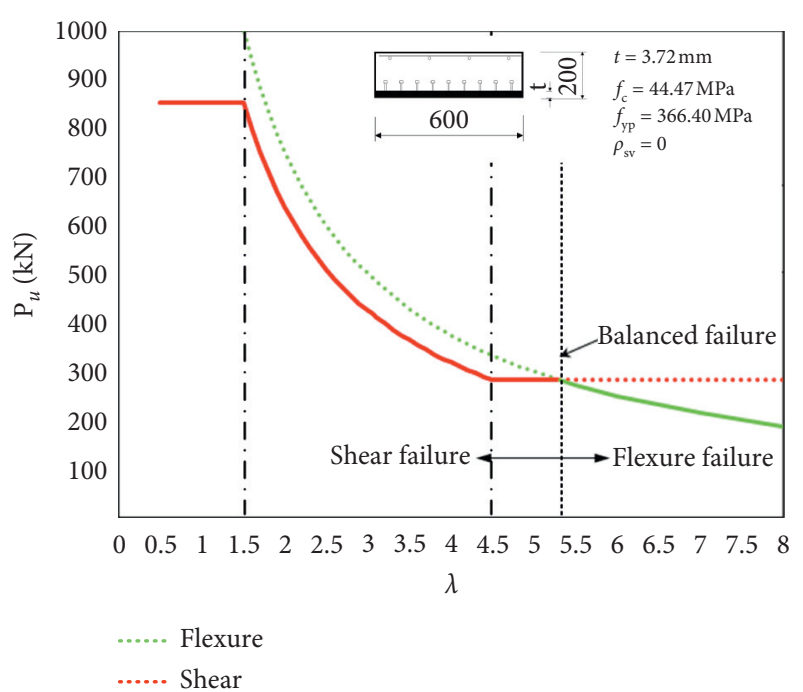

(a)

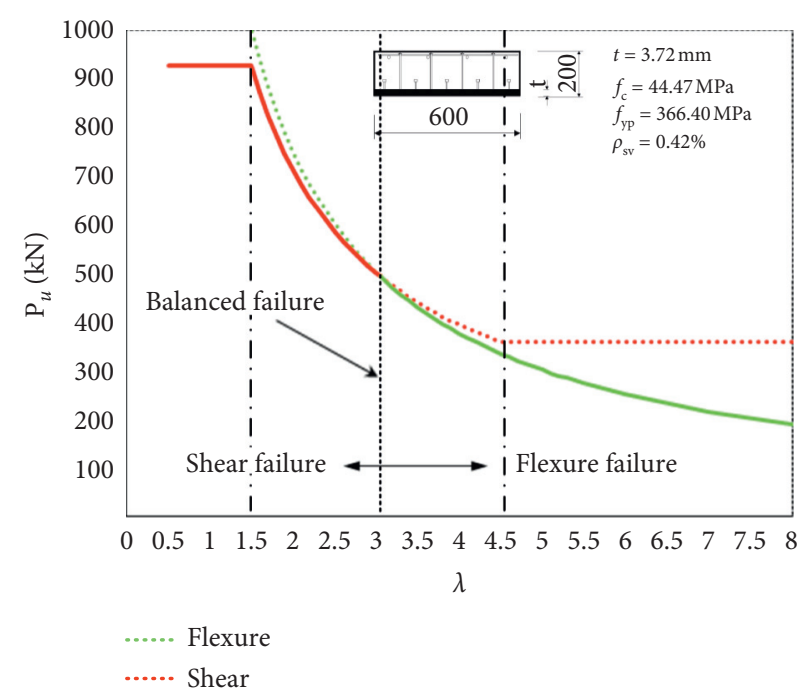

(b)

Figure 23: Ultimate load versus shear span ratio curves: (a) $\rho_{\mathrm{sv}}=0 \%$; (b) $\rho_{\mathrm{sv}}=0.42 \%$.

with shear span ratio can be obtained by the equations of flexural strength and shear strength described above. The results are shown in Figure 23. Two $P_{\mathrm{u}}-\lambda$ curves can be obtained from equations of flexural and shear strength. If $\rho_{\mathrm{sv}}=0$, the two curves intersect at one point with $\lambda=5.4$, which means balanced failure. When $\lambda<5.4$, the shear failure occurs. When $\lambda>5.4$, the flexure failure occurs. If $\rho_{\text {sv }}=0.42 \%$, the two curves intersect at one point with $\lambda=3.1$, which means balanced failure. When $\lambda<3.1$, the shear failure occurs. When $\lambda>3.1$, the flexure failure occurs.

\section{Conclusions}

In this study, fifteen specimens were tested by three-point and four-point symmetric loading. The flexural and shear strengths were calculated. The main conclusions in this study are summarized as follows:

(1) The failure modes of Half-SC slabs can be basically recognized as flexural, shear, and balanced failure. When the studs meet the requirements of full composite connection, the relative slippage between the steel faceplate and the concrete is negligible. When the number of studs does not meet the requirement of full composite connection, Half-SC slabs will fail ahead of material failure owing to serious slippage between the concrete and steel plate.

(2) Flexural failure is characterized by the tensile yielding of the steel plate and the crushing of concrete. With the increase of the thickness of the steel faceplate, the ultimate strength improves obviously and the ductility reduces, the failure of the specimen will gradually change from ductile to brittle. The increase of the stud number has an obvious effect on the increase of ductility but the effect on ultimate strength is inconspicuous.
(3) Shear failure is caused by the splitting of concrete between the loading point and support or by the excessive plastic deformation of steel faceplate. The concrete and steel faceplate have different contributions to shear capacity and the ultimate strength depends on which of the two contributes most to shear capacity. This is significantly different from that of the reinforced concrete slabs.

(4) As far as shear failure is concerned, when the shear span ratio $\lambda>1.5$, the steel plate in the shear-compression zone would achieve yield strength and the bottom plate plays a significant role in shear failure owing to the membrane action. The failure is ductile and the ultimate strength decreases with the increase of the shear span ratio. When the shear span ratio $\lambda \leq 1.5$, the plastic development of the steel plate is incomplete. The stud number has a positive correlation with the du'ctility coefficient of the specimen but has an insignificant effect on the ultimate strength.

(5) The flexural strength is calculated. Based on a tiearch model, the calculation equation of shear strength is proposed. The calculated results agree well with the experimental data. The failure mode depends on the minimum value between the flexural and shear strengths.

\section{Data Availability}

The data used to support the findings of this study are available from the corresponding author upon request.

\section{Disclosure}

However, the opinions presented in this paper do not necessarily reflect the views of the sponsors. 


\section{Conflicts of Interest}

The authors declare that they have no conflicts of interest.
[13] M. Saichi and H. Shinohe, "Damage estimation for concrete with averaged stress-strain curve," Concrete Research and Technology, vol. 10, no. 2, pp. 73-82, 1999, in Japanese.

\section{Acknowledgments}

This work was supported by the National Natural Science Foundation of China (Grant no. 51778032). The authors greatly appreciate the financial support.

\section{References}

[1] A. Kaneuji and Y. Okuda, "Feasibility study of concrete filled steel (SC) structure for reactor building," in Proceedings of the 10th International Conference on Structural Mechanics in Reactor Technology, SMiRT 10, Anaheim, CA, USA, August 1989.

[2] K. Ichikawa, O. Isobata, and S. Kawamata, "Design and analysis of reactor containment of steel-concrete composite laminated shell," in Proceedings of the 4th International Conference on Structural Mechanics in Reactor Technology, SMiRT 4, San Francisco, CA, USA, August 1977.

[3] R. Pan, J. Wu, and X. Zhang, "Application and development of steel plate reinforced concrete structure in nuclear power engineering," Industrial Construction, vol. 44, pp. 1-7, 2014, in Chinese.

[4] F. Sun and R. Pan, "Nonlinear finite element analysis of a test on the mechanical mechanism of the half-steel-concrete composite beam in HTR-PM," Nuclear Engineering and Design, vol. 305, pp. 461-464, 2016.

[5] Y. Zhao, X. Liu, and J. Mu, "Construction technology for steel reinforced concrete composite structure of super high-rise building," Construction Technology, vol. 45, pp. 84-87, 2016, in Chinese.

[6] Y. Yang, G. Zhu, P. Zhou, J. Nie, and B. Xie, "Experimental study on the mechanical behavior and design method of plain steel-plate and concrete composite bridge decks," China Civil Engineering Journal, vol. 42, pp. 135-141, 2009, in Chinese.

[7] S. Akita, G. Kitano, S. Nakazawa, H. Osuga, T. Yamaguchi, and N. Tatsuo, Experimental Study on a Concrete Filled Steel Structure Part 18 Shear Tests (Experimental Study on Half SC Panels), Architectural Institute of Japan, Tokyo, Japan, in Japanese, 1998.

[8] M. Takeuchi, F. Fujita, A. Funakoshi, R. Shohara, S. Akira, and R. Matsumoto, "Experimental study on steel plate reinforced concrete structure, part 2: response of SC members subjected to out-of-plane load (outline of the experimental program and the results)," in Proceedings of the Annual Conference of Architectural Institute of Japan, pp. 1037-1038, in Japanese, Tokyo, Japan, 1999.

[9] Y. Yang, J. Liu, J. Fan, and X. Nie, "Experimental study on flexural capacity of steel plate-concrete composite slabs," Journal of Building Structures, vol. 34, pp. 24-31, 2013, in Chinese.

[10] L. Wu, Y. Jiang, D. Zhang, and M. Yan, "Flexural behavior and bearing capacity of simply supported steel plate-concrete composite slab," Journal of Building Structures, vol. 36, pp. 125-134, 2015, in Chinese.

[11] GB/T5782-2000, Hexagon Head Bolts, Standards Press of China, Beijing, China, 2000.

[12] GB50010-2010, Code for Design of Concrete Structures, Ministry of Housing and Urban-Rural Construction of the People's Republic of China, Beijing, China, 2009. 